\title{
A água é uma máquina do tempo
}

1.

Às vezes o detalhe de um desenho, que antes parecia apenas uma mancha, se torna uma marca com contornos definidos. Nessa hora, reconhecemos como tudo começou. Foi assim quando comecei a falar mais sobre o meu trabalho e a localizar suas respirações, suas águas, suas vibrações. O corpo viu primeiro e descobriu de onde vinha tudo aquilo. Tudo que precisava ser expressado, falado, não contido. Este texto dá forma a algumas dessas articulações, revela suas linhas de força e vidas dentro da vida. Se "a respiração é a rainha do corpo", ${ }^{1}$ este texto incorpora essa ação e também se contrai e se expande de acordo com sua própria respiração, enquanto você o lê.

Muito do meu trabalho é sobre minha própria família, especialmente sobre minha avó. As avós concentram as forças de cura em nossa comunidade. Ao mediar conflitos, as avós sabem que conflito é fundamento, e mediação de conflito também é fundamento. Portanto, no meu caso, linhagem é linguagem. A performance de uma avó é uma performance coletiva de todas as avós. É a performance de toda uma linhagem de mulheres, que se manifesta em multimeios e multidireções, atuando e enfrentando várias camadas afetivas, por vezes traumáticas. São plurivozes ancestrais.

Seria possível fabular novos laços de parentescos, novas linhagens e até mesmo uma nova filiação? Faço esta pergunta, norteadora do meu trabalho, partindo do conceito de fabulação crítica proposto por Saidiya Hartman. ${ }^{2}$ Unindo duas palavras que parecem opostas, ela localiza o fabular no campo da imaginação política; e situa a crítica, não como uma prática de hierarquização que nomeia, categoriza e constrói cânones e narrativas hegemônicas, mas a partir de uma perspectiva de desenvolver uma criticidade em torno do material de arquivo. Dessa maneira, quando faço uso de material de arquivo nas minhas obras, procuro discutir se existe uma linguagem diaspórica comum e para qual caminho de intersecções coincidentes essa linguagem apontaria. As lacunas, falhas e abismos desse arquivo são como cartografias sobrepostas de paisagens internas e externas ${ }^{3}$ ainda a serem desenhadas. Se há um conjunto de experiências diaspóricas 
compartilhadas, a reconstituição de um território é a reconstituição do próprio ser. A fragmentação se torna metodologia e impulso criativo.

"Inventar a partir de um inventário", disse Tiganá Santana numa entrevista, baseando-se em um poema de Jorge Portugal. Com essa frase, Tiganá une duas palavras, que aparentemente também se contradizem: inventar e inventário. Nesse sentido, percebo que o inventário não é só um conjunto de documentos, mas também o acervo emocional de nossas famílias. São acervos geracionais.

Buscando criar uma justaposição de tempos, frequentemente começo os meus trabalhos construindo as fotografias, e essas fotografias acabam virando frames. Os frames, alinhados em sequência, viram filmes. Cada filme contém todos os filmes, os que eu já fiz e os que ainda vou fazer.

Assim como cada frame contém todos os frames do filme inteiro, eu imagino que eles funcionam como células, e essas células são como sementes, que contêm todo o resto da criação.

Cada frame é construído de modo a conter todas as temporalidades: o passado, uma presentificação do passado e uma dimensão um pouco distópica de futuro. Tal sentido de futuricidade, assim como este texto, tem um caráter oracular. A futuricidade pode ser percebida como uma premonição de algo que já aconteceu e que reverbera em dimensões de tempo instáveis e permeáveis. Assim, é possível atravessá-las.

2.

"Aonde não chegamos, o céu caiu" - em kikongo, "kunaketwaluaka-ko zulu dyabwa" - é um provérbio bakongo mencionado pelo poeta e professor Abreu Paxe ${ }^{4}$ em sua tese de doutorado. Ele comenta especificamente sobre essa sentença proverbial da seguinte forma:

Esse provérbio em si já se revela responsável por contínuas passagens de umas coisas pelas outras de modo incessante. Vê-se mesmo que quando ele se agita, revela o caráter explosivo, tumultuoso e infinito de seus tráfegos relacionais, em que as coisas entre si pulam uma nas outras e com as coisas; por isso, o centro não se encontra em lado algum.

Talvez desatando o enigma contido nesse provérbio, Tiganá Santana costuma dizer que no centro da roda não há segredo, há mistério. A meu ver, um centro que se move, um centro que dança ao redor de si mesmo e com as extensões de suas pluralidades não se fixa em um único destino.

Por entender essas formulações como sínteses temporais, como fixadoras de memória e também como meios de passagem de conhecimento, tenho me aprofundado no estudo dos provérbios, principalmente os centro-africanos. O professor Paxe diz que os provérbios são, em essência, uma ficcionalização da vida e uma textualização de elementos do cotidiano. Esse procedimento oferece uma chave de leitura possível da minha prática 
artística. Em um contínuo retorno a si mesmo, observo que, na maioria dos meus trabalhos, há jogos de palavras cifrados, onde o centro está presente, mas é subentendido.

Dois conceitos fundamentais, que tangenciam minha poética, nascem justamente da circularidade dessas proposições e são baseados em cosmologias centro-africanas. São cosmopercepções Congo-Angola e, por conseguinte, afro-brasileiras de apreensão do mundo. ${ }^{5}$

O primeiro deles é o culto aos ancestrais, que consiste em lembrá-los, honrá-los, alimentá-los.

O segundo conceito parte de uma conexão profunda com a natureza e entende que os ciclos da vida estão intrinsecamente conectados aos ciclos da natureza. Numa sistematização do chamado "Cosmograma Bakongo", a duração de um único dia está ligada ao ciclo de vida e morte de todos os seres. Ao acionar o cosmograma, um ser nasce às seis da manhã, torna-se maduro ao meio-dia, envelhece às seis da tarde e se inscreve como um ancestral à meia-noite. Com estes diferentes graus de fisicidade, o ciclo se repete todos os dias de maneira circular, transmutacional e interrelacional. O que separa as dimensões dos vivos e dos mortos é uma linha fina de água chamada Kalunga. Nessa forma de ver o mundo, a água guarda memória, a água é vista como um veículo, a água é uma máquina do tempo. É uma iniciação.

A máquina Kalunga é uma máquina de ver o invisível com seus olhos d’água. ${ }^{6}$

Quase a ponto de velar o que foi capturado, a máquina Kalunga verte imagens, ativando as qualidades refrativas e reflexivas das entidades que mobiliza, tal como uma câmera controla quanto de luz é capaz de passar pelo obturador sem apagar os vestígios do que enquadra.

A máquina Kalunga é um aparato emancipatório.

\section{3.}

Uma vez ouvi de Alexis Pauline Gumbs que o primeiro teletransporte foi o nosso nascimento. Indo mais fundo nessa ideia, eu me dei conta de que, na fisiologia da gestação, os fetos respiram pelo coração e pelo cordão umbilical, que faz as trocas gasosas. Na hora do nascimento, o bebê respira pelo nariz pela primeira vez, muitas vezes limpando as vias respiratórias de fluidos. Essa inspiração que escoa os líquidos e expande os pulmões parece doer um pouquinho, o bebê chora. O choro ecoa na sala de nascimento, reverberando vibrações sonoras e conferindo um senso de espacialidade ao próprio recém-nascido. 0 ruído agudo se modula, como o sonar de um mamífero marinho, com o bebê já testando, talvez, uma afinação de sua voz com a voz da vida que inicia. Os olhos piscam tirando fotografias desfocadas. Ao sair de um mundo aquático para o mundo aéreo, o bebê respira e vê, ao mesmo tempo, pela primeira vez. Ouve seu próprio choro.

Isso deve ter me marcado de tal modo que consigo intuir que minha primeira experiência de cinema foi o meu próprio nascimento. A sala de cinema, escura e com imagens agigantadas em projeção, me fascinou desde sempre e me deixava confortável a ponto 
de dormir como se estivesse em casa, minha mãe dizia. Talvez transportada a algum lugar em forma de céu noturno com seus vislumbres de sonhos e estrelas fulgurantes. Ao nascer, os olhos se abriram e projetaram um filme. Uma primeira ficção.

\section{4.}

Epistemologia da umbigada. Um dia, observando uma roda de jongo, eu percebi que era exatamente esse giro epistemológico que eu estava fazendo nos meus processos artísticos. Vista a centralidade que o umbigo tem para as culturas centro-africanas e afro-brasileiras, falar sobre o próprio umbigo não se configura um ato de espelhamento narcísico.

Pelo contrário. Do mesmo modo que as giras oceânicas que saem de Angola e banham o Brasil são correntes em sentido anti-horário, a gira refaz o caminho do sol, de leste para oeste, círculos de corpos que se movimentam em espiral. Nesta dança, eu projeto meu umbigo para a frente e convido alguém para se juntar a mim no centro da roda. Quando lanço meu corpo ao centro, eu piso na intersecção de uma linha horizontal, que é a Kalunga, e uma linha vertical, que representa minha espinha dorsal, meus alicerces. A intersecção dessas duas linhas é a encruzilhada. Nesse ponto de encontro, posso riscar as assinaturas espirituais dos meus antepassados, bússolas do bem-viver, curas intergeracionais. É o espaço onde se pode ouvir a pergunta e a resposta simultaneamente.

Quando estou no meio da roda, o lugar onde o céu ainda não caiu, eu dou uma umbigada no tempo. Dou uma umbigada em meus ancestrais. Dou uma umbigada em mim mesma.

\section{NOTAS}

\footnotetext{
* Aline Motta Nasceu é bacharel em Comunicação Social pela UFRJ e pós-graduada em Cinema pela The New School University (NY). Combina diferentes técnicas e práticas artísticas, mesclando fotografia, vídeo, instalação, performance, arte sonora, colagem, impressos e materiais têxteis. Sua investigação busca revelar outras corporalidades, criar sentido, ressignificar memórias e elaborar outras formas de existência. Foi contemplada com o Programa Rumos Itaú Cultural 2015/2016, com a Bolsa ZUM de Fotografia do Instituto Moreira Salles 2018 e com $7^{\circ}$ Prêmio Indústria Nacional Marcantonio Vilaça 2019. Recentemente participou de exposições importantes como "Histórias Feministas, artistas depois de 2000" - MASP, "Histórias Afro-Atlânticas" - MASP/Tomie Ohtake, "Cuando cambia el mundo" - Centro Cultural Kirchner, Buenos Aires, Argentina e "Pensar tudo de nuevo" - Les Rencontres de la Photographie, Arles, França. Abriu sua exposição individual "Aline Motta: memória, viagem e água” no MAR/Museu de Arte do Rio em 2020. Em 2021 exibiu seus trabalhos em vídeo no New Museum (NY) no programa "Screen Series".
} 
${ }^{1}$ Sodré, Muniz. Pensar Nagô. Petrópolis: Vozes, 2017, p. 117.

${ }^{2}$ Hartman, S. "Vênus em dois atos". Revista ECO-Pós, vol. 23, n 3, pp. 12-33. Disponível em: https://revistaecopos.eco.ufrj.br/eco_pos/article/view/27640.

${ }^{3}$ Conceito de paisagens internas e externas concebido pela escritora Sheyla Smanioto.

${ }^{4}$ Paxe, Abreu Castelo Vieira dos. "A migração fractal do provérbio: práticas, sujeitos e narrativas entrelaçadas". Tese de doutorado, Programa de Estudos Pós-Graduados em Comunicação e Semiótica - PUC/SP, 2016. Orientador: José Amálio de Branco Pinheiro.

${ }^{5}$ Os trabalhos Corpo Celeste II e III (2019/2020), que realizei em colaboração com o historiador e etnomusicólogo Rafael Galante, por exemplo, são baseados em seu curso “As diásporas centro-africanas e a formação das musicalidades afro-atlânticas", entre outros, e sistematizaram muitos dos conceitos aqui apresentados.

6 “Olhos d'água” é o título de um livro de Conceição Evaristo. Evaristo, Conceição. Olhos d'água. Rio de Janeiro: Pallas Editora, Fundação Biblioteca Nacional, 2016. No texto para o podcast “Águas de Kalunga” (ep.1, Museu de Arte do Rio/MAR, 2019), escreveu Conceição Evaristo: "Kalunga, segundo as minhas mais velhas e os meus mais velhos, antes estava na lembrança de nossas águas matriciais, princípio da vida. Águas de Kalunga, reino de nossas ancestralidades, ali estavam os entes que nos guardam no fundo dos olhos. Kalunga, águas de vir e ir naturalmente. Princípio e retorno. As águas de Kalunga são águas mães, são geradoras de tudo". 